\title{
The Effect of Fact-checking on Elites: A field experiment on U.S. state legislators
}

\author{
Brendan Nyhan \\ Department of Government \\ Dartmouth College \\ nyhan@dartmouth.edu
}

\author{
Jason Reifler \\ Department of Politics \\ University of Exeter \\ j.reifler@exeter.ac.uk
}

\begin{abstract}
Does external monitoring improve democratic performance? Fact-checking has come to play an increasingly important role in political coverage in the United States, but research suggests it may be ineffective at reducing public misperceptions about controversial issues. However, fact-checking might instead help improve political discourse by increasing the reputational costs or risks of spreading misinformation for political elites. To evaluate this deterrent hypothesis, we conducted a field experiment in nine U.S. states in which a randomly assigned group of state legislators were sent a series of letters about the risks to their reputation and electoral security if they are caught making questionable statements. The legislators who were sent these letters were substantially less likely to receive a negative fact-checking rating or to have their accuracy questioned publicly, suggesting that the threat posed by fact-checking can reduce inaccuracy in statements made by political elites.
\end{abstract}

Funding support was provided by the Democracy Fund and New America Foundation. We thank Kevin Esterling, Tom Glaisyer, Michael Herron, Donald P. Green, and audiences at Duke University and Dartmouth College for helpful comments. We are also grateful to Eric Yang and Eli Derrow for excellent research assistance. 
To what extent can external monitoring increase political accountability and improve democratic outcomes? Social scientists are increasingly using field experiments to understand the ways in which monitoring can shape political and bureaucratic behavior (e.g., Duflo, Hanna, and Rya 2012; Olken 2007; Ferraz and Finan 2008; Grose N.d.; Butler 2010; Humphreys and Weinstein N.d.; Malesky, Schuler, and Tran 2012). One important source of external monitoring for politicians in free societies is the press. In the United States, several fact-checking organizations have begun to systematically evaluate the accuracy of statements made by politicians at the national and state level using a journalistic approach (Graves and Glaisyer 2012), but little systematic evidence exists on the effectiveness of this practice.

Research in political science and psychology suggests a number of reasons for skepticism that fact-checking will successfully reduce public misperceptions (for reviews, see Nyhan and Reifler 2012 and Lewandowsky et al. 2012). First, people often seek to avoid unwelcome information about politics, which may reduce exposure to fact-checks that challenge their existing beliefs (Taber and Lodge 2006; Stroud 2008; Iyengar et al. 2008; Iyengar and Hahn 2009). ${ }^{1}$ In addition, corrections may be ineffective or even make misperceptions worse among individuals who do encounter counter-attitudinal corrective information about controversial issues ( $\mathrm{Ny}$ han and Reifler 2010; Nyhan, Reifler, and Ubel 2013).

It is possible, however, that fact-checking might have positive effects on elite behavior by increasing the reputational costs or risks of spreading misinformation (Nyhan 2010). Though a pollster for a U.S. presidential candidate famously said

\footnotetext{
${ }^{1}$ One study found that visitors to fact-checking websites show higher levels of factual knowledge controlling for certain observable characteristics (Gottfried et al. 2013), but these differences could reflect self-selection among the fact-checking audience rather than causal effects.
} 
"We're not going to let our campaign be dictated by fact checkers" (Smith 2012) and some pundits have written off the practice as ineffective at the presidential level (Carr 2012; Balz 2012), the fact that factually questionable statements continue to be made does not demonstrate that fact-checking is ineffective. The relevant question is whether more misleading or inaccurate statements would be made in the absence of fact-checkers. Just as greater accountability could help pundits make more accurate predictions (Tetlock 2005), scrutiny from fact-checkers could increase politicians' concerns about accuracy and encourage them to make fewer misleading or inaccurate statements. Previous research indicates that elected officials are very concerned about threats to their re-election (Mayhew 1974; Fenno 2002). While most fact-checking likely has little effect on a politician's re-election prospects, monitoring by fact-checkers should increase the perceived risk of a damaging disclosure, particularly for Congressional or state candidates who attract less media coverage and advertise less extensively than presidential candidates.

To evaluate this deterrent hypothesis, we conducted the first field experiment to evaluate the effect of fact-checking in nine U.S. states before the November 2012 general election. In this experiment, we randomized whether or not state legislators were sent a series of letters designed to increase legislators' concerns about accuracy and the potential electoral and reputational consequences of being factchecked. Because we conducted the study in states where PolitiFact state affiliates were operating, the threat that dubious claims could be exposed should have been credible. Our results indicate that state legislators who were sent letters about the threat posed by fact-checkers were less likely to have their claims questioned as misleading or inaccurate during the fall campaign-a promising sign for journalis- 
tic monitoring in democratic societies.

\section{The effect of fact-checking on politicians}

While major news organizations in the United States have long sought to ensure the accuracy of the facts that they report (e.g., quoting public figures correctly), they frequently refrain from questioning the accuracy of contested claims made by public figures even when the statements are verifiable - a practice that media often critics attribute to the journalistic norm of objectivity (e.g., Cunningham 2003). Politicians appear to exploit this norm, which enables them to publicize questionable claims with little risk of being contradicted (e.g., Fritz, Keefer, and Nyhan 2004).

The fact-checking movement takes a very different approach in focusing exclusively on evaluating the accuracy of claims made by politicians and political elites. Fact-checking by the three elite fact-checkers (PolitiFact and its state affiliates, Factcheck.org, and the Washington Post Fact Checker) and other media organizations has come to play an increasingly important role in political coverage in the United States (Graves and Glaisyer 2012) and is now beginning to expand abroad (Adair 2013; Alcorn 2013). This movement represents a potentially radical change in how journalism is practiced with significant consequences for political accountability and democratic discourse. Rather than limiting itself to the "he said," "she said" coverage and horse race analysis that dominate traditional political news, the fact-checkers devote their energies and resources to scrutinizing what politicians say and rendering public judgments about the correctness of their claims.

What effects does fact-checking have on politicians? This question has not 
been examined systematically, but previous research suggests that legislators may be sensitive to media scrutiny of the sort that fact-checkers provide. The literature on Congressional behavior shows that legislators are concerned about re-election and engage in risk-averse behavior to minimize potential electoral or reputational threats (Mayhew 1974; Fenno 2002). One potential threat that elected officials may be concerned about is critical media coverage. Studies have found that coverage levels of politicians vary widely (Arnold 2004; Campante and Do 2013) and that those differences in coverage can have significant consequences for the incumbency advantage in elections (Prior 2006; Schulhofer-Wohl and Garrido 2009; Gentzkow, Shapiro, and Sinkinson 2011), legislator performance in office (Snyder and Strömberg 2010), and possibly even state-level patterns of corruption (Campante and Do 2013). Fact-checking thus has the potential to create career risks for politicians by generating negative coverage for politicians that could damage their reputation and credibility. Anecdotal evidence suggests that some candidates seek to avoid the negative ratings given out by fact-checkers or alter claims that come under fire, though others disavow such concerns (Graves 2013; Gottfried et al. 2013).

\section{Experimental design}

Observational analyses of the effects of fact-checking on politician behavior could easily lead to incorrect conclusions. For instance, fact-checks may be more widely used in states that already had stronger accuracy norms in public discourse, a confound which might falsely suggest that fact-checking reduced inaccuracy in those states. Alternatively, fact-checks might seem to be ineffective because certain leg- 
islators keep making questionable statements despite receiving negative ratings, but we cannot determine which legislators are not making such statements because of the presence of fact-checkers using observational data alone.

To overcome these inferential difficulties, we conducted a field experiment in fall 2012 in nine U.S. states in which PolitiFact affiliates were operating (Florida, New Jersey, Ohio, Oregon, Rhode Island, Tennessee, Texas, Virginia, and Wisconsin), excluding only the two states where the authors are based (Georgia and New Hampshire) due to concerns about treatment effect heterogeneity. (See Supporting Materials $[\mathrm{SM}]$ for the distribution of legislators across states.) Because we could not randomize the activities of fact-checking organizations, we instead employed randomized correspondence, which has frequently been used in previous field experimental studies of elite political behavior (Bergan 2009; Broockman 2013; Butler and Broockman 2011; Butler and Nickerson 2011; Butler, Karpowitz, and Pope 2012; Loewen and MacKenzie N.d.; Loewen and Rubenson 2011; McClendon N.d.). In this case, we randomized whether legislators were sent a series of letters about the reputational or electoral consequences of receiving a negative rating from a fact-checking organization.

We chose to conduct our study with state legislators for several reasons. First, we could assemble a very large sample — far larger than would be possible in the U.S. Congress. Second, theory suggests that state legislators should be more sensitive to an individual fact-check than a member of Congress because they are covered by the media less frequently, which means that a single bad story or negative rating will be a larger proportion of their total coverage. State legislators also have more limited financial resources and thus cannot rely on televised advertising 
or direct mail to the same extent as members of Congress. By targeting a lowerlevel politician in this way, we increase the effect of our treatment. Finally, it was more feasible to reach state legislators through correspondence than members of Congress, who typically have much larger offices and more professional staff and interns. In a Congressional office, for instance, it would be rare for a legislator to directly open and read incoming mail, which is primarily handled by staff whose primary responsibility is constituent correspondence. Our mailings would therefore be unlikely to have any direct effect on Congressional behavior. However, state legislators often have few or no professional staff, substantially increasing the likelihood that they would encounter and read our mailings.

\section{Experimental conditions}

Our experiment randomized whether state legislators were sent a series of letters about the reputational or electoral consequences of fact-checking. 1169 legislators from the nine states in our sample ${ }^{2}$ were randomly assigned to one of three conditions: a treatment condition in which legislators were sent letters reminding them of the risks to their reputation and electoral security if they are caught making questionable statements, a placebo (Hawthorne) condition in which legislators were sent letters stating that we were monitoring campaign accuracy, and a control condition. While legislators of course vary in the likelihood that they will make misleading or inaccurate statements or be the target of fact-checking, this randomization procedure (which is described further below) ensures that these individual-level differences are independent of treatment assignment, which allows us to obtain an

\footnotetext{
${ }^{2}$ See SM for the distribution of legislators across states.
} 
unbiased estimate of the treatment effect.

Specifically, legislators in the treatment and placebo (Hawthorne) conditions were sent three separate mailings (mail dates: August 23, September 18, and October 12, 2012), while those in the control condition were not contacted. Because the state legislatures in question were out of session during our study, we sent a copy of each mailing to legislators' capitol and district addresses (see SM for details).

\section{Treatment condition}

In the treatment condition, legislators were sent a series of letters that emphasized the risks of having misleading or inaccurate statements exposed by fact-checkers. The treatment mailing to legislators had several key elements: (1) a reminder of the presence of a PolitiFact affiliate in their state to establish the credibility of the threat of being fact-checked; (2) a description of the potential electoral and reputational consequences of negative fact-check ratings; and (3) two sample PolitiFact "pants on fire" fact-checks (balanced by party) to heighten legislators' concerns about being fact-checked from one of the states excluded from our study. (See SM for the full text of a sample letter.)

\section{Hawthorne (placebo) condition}

In addition to our treatment letter, we designed a placebo letter that alerted legislators that we were conducting a study of the accuracy of statements made by politicians, but excluded any language about fact-checking or the consequences of inaccurate statements. We included this additional condition to account for what is known as a Hawthorne effect - the tendency for experimental participants to behave 
differently when they know they are being studied, which can confound treatment effect estimates (Levitt and List 2011). By including a placebo condition, we can determine whether legislators responded to the specific content of the treatment letter or the fact that they were being studied. (See SM for full text of a sample letter.)

\section{Control condition}

Legislators in the control condition were not sent mailings or contacted in any way.

\section{Randomization and balance}

Using the R package blockTools (Moore N.d.), we block randomized assignment to ensure perfect balance between conditions on state, political party, legislative chamber (state house/state senate), and whether or not a legislator had previously received a PolitiFact rating. We also used multivariate continuous blocking to maximize balance between conditions on two continuous covariates that could be related to being fact-checked: previous vote share and fundraising (Moore 2012). In this way, we sought to minimize variance in factors other than our experimental conditions that would influence whether or not legislators would be fact-checked during the study period, which increases the precision of experimental treatment effect estimates (Duflo, Glennerster, and Kremer 2007).

This block randomization resulted in near-perfect balance between conditions among the 1169 legislators included in the study, as Table 1 and Figure 1 indicate. $^{3}$ Importantly, this blocking also results in balance on observables that were not in-

\footnotetext{
${ }^{3}$ Of the 1197 legislators in our sample, 1169 were randomized within 69 blocks; 28 were dropped to maximize balance. Of the 69 blocks formed, 50 had equal numbers of legislators in each condition and 19 had one fewer legislator in a single condition.
} 
clude in the blocking like being a party leader or a committee chair. ${ }^{4}$

Table 1: Covariate balance by experimental condition

\begin{tabular}{lcc}
\hline & Treatment & Placebo/Control \\
\hline GOP & 0.56 & 0.56 \\
State senate & 0.26 & 0.26 \\
Previous fact-check & 0.21 & 0.21 \\
Log fundraising & 11.6 & 11.5 \\
Previous voteshare & 71.6 & 71.3 \\
Party leader & 0.07 & 0.07 \\
Committee leader & 0.53 & 0.51 \\
\hline
\end{tabular}

(weighted means)

\section{Estimand: Assignment to treatment condition}

Because it is impossible to know with certainty which legislators read the treatment letter, our experiment estimates the effect of being assigned to the treatment condition. As a partial indicator of which legislators read our mailings (and to further indicate the importance of the letter), we asked recipients of treatment and placebo letters to sign and return an enclosed postage-paid acknowledgment postcard. However, those postcards cannot be used to estimate the actual effect of reading the treatment letter. First, many legislators may have read the letter but not bothered to return the postcard. In addition, the postcards themselves provide suggestive evidence that the content of the treatment letter had a significant effect-only $21 \%$ of legislators in the treatment group returned a signed postcard compared to $34 \%$ of

\footnotetext{
${ }^{4}$ Texas state representative J.M. Lozano was mistakenly coded as a Democrat; he actually switched to the Republican Party in spring 2012. The randomization procedure was carried out with him coded as a Democrat. After his affiliation was corrected, however, the sample remains balanced by party ( $56 \%$ in both the treatment and placebo/control conditions).
} 
Figure 1: Covariate balance: Vote share and fundraising $(\log )$
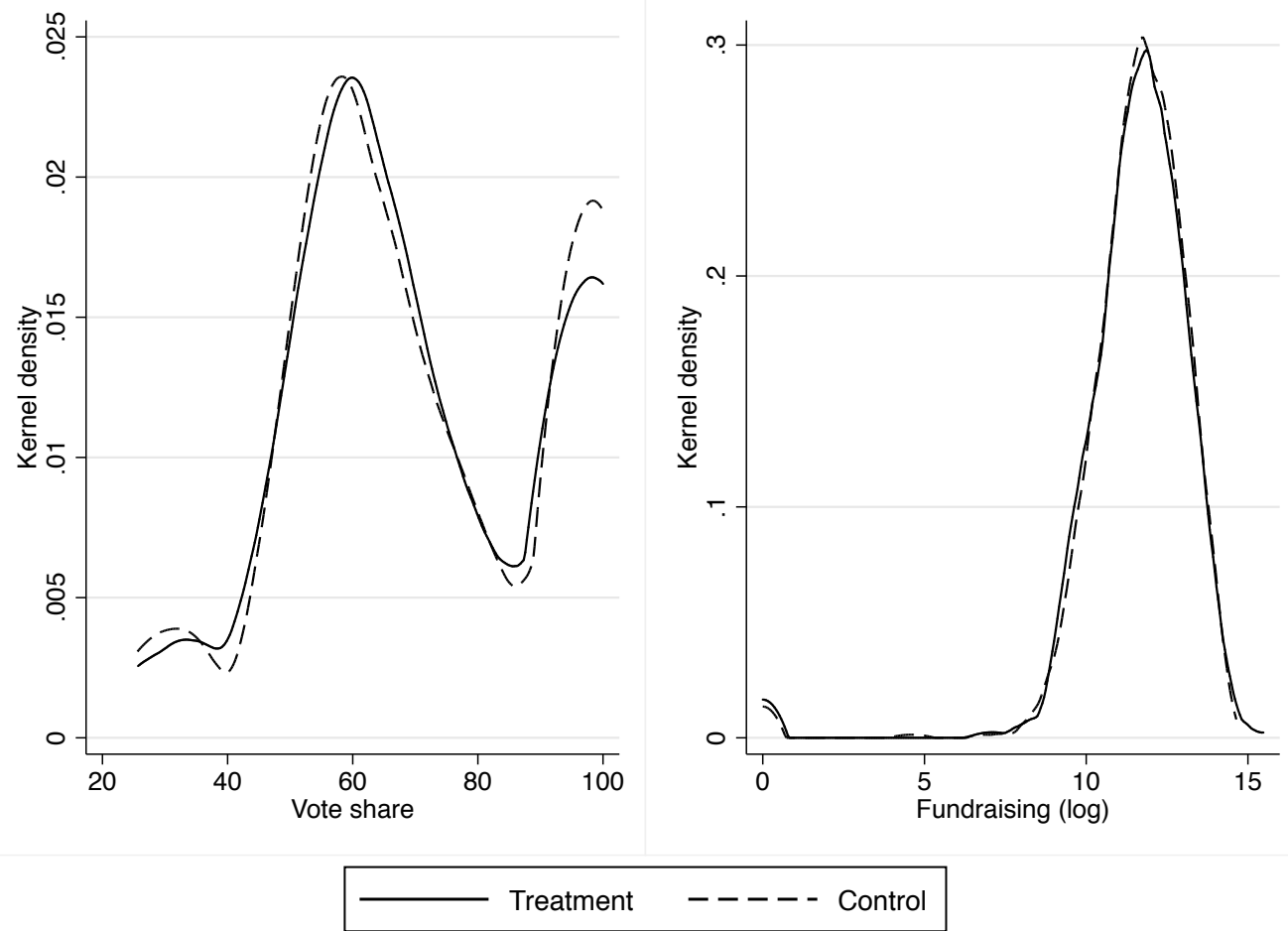

(weighted densities)

those in the placebo condition, suggesting that it may have displeased its recipients $(p<.01 ;$ see SM). Alternatively, we could use successful delivery of the letter as an indicator of treatment receipt, but only $0.4 \%(n=18)$ of our 4,661 letters were returned as undeliverable, so the treatment effect estimates would be virtually identical. We therefore estimate the expected difference in outcomes resulting from assignment to the treatment condition (rather than receipt of treatment). ${ }^{5}$

In addition, we assume that outcomes are unaffected by the experimental condi-

\footnotetext{
${ }^{5}$ However, we summarize what our estimates would be for the average treatment effect on the treated under different assumptions about the (unmeasurable) probability that legislators actually received the treatment in the results section below.
} 
tions to which other legislators are assigned. A violation of this assumption would occur, for example, if a legislator who received our treatment letter showed the letter to a legislator in the control group and thereby affected the likelihood that she would make misleading or inaccurate statements. We believe this assumption is justified for two reasons. First, all of the state legislatures in our study were out of session during the study period, which should have dispersed legislators across their districts, substantially reducing the opportunity for treatment spillover. In addition, any spillover would bias our treatment effects toward zero, reducing the likelihood that we would find significant effects.

\section{Outcome measures}

Due to the complexities of language and politics, no perfectly objective measure of statement accuracy has yet been created. It was also infeasible to code every statement during the study period by all the state legislators in our data, especially since most are unobservable to researchers. As such, we examine three measures of public criticism by fact-checkers or others that question the validity or accuracy of statements made by state legislators in our sample. Such factual criticism should be more likely as the frequency of misleading or inaccurate statements by state legislators in our sample increases.

The first dependent variable is whether a legislator received a negative rating from the PolitiFact affiliate in their state. ${ }^{6}$ PolitiFact uses a six-point scale to rate the accuracy of statements, ranging from "True" to "Pants on Fire." Because our

\footnotetext{
${ }^{6}$ The PolitiFact affiliates were not aware of our experiment or the treatment conditions to which legislators were assigned except in one case discussed in the SM.
} 
unit of analysis is the state legislator, we created a binary measure (Negative PolitiFact rating) of whether a state legislator was rated by PolitiFact as having made a misleading or inaccurate statement during the study period of August 24-November 6,2012 . This measure, which is based on PolitiFact's description of the meaning of their rating categories, takes a value of 1 if the state legislator received a rating of "half true" ("partially accurate but leaves out important details or takes things out of context"), "mostly false" ("contains some element of truth but ignores critical facts that would give a different impression"), "false" ("not accurate"), or "pants on fire" ("not accurate and makes a ridiculous claim") during the study period and 0 otherwise, which could include PolitiFact ratings of "true" or "mostly true" or, most commonly, if the legislator had no statements publicly evaluated by PolitiFact (PolitiFact.com N.d.).

One potential concern is whether PolitiFact truth ratings are consistent and accurate. The franchise training model used by PolitiFact for its state affiliates suggest that these ratings should be comparable across states (Myers N.d.; Nyhan 2013a). While individual fact-checks sometimes veer into punditry or semantic disputes (Marx 2012; Nyhan 2012, 2013b), an academic analysis of the ratings by elite factchecking organizations finds a very high level of agreement when they evaluate identical or similar claims (Amazeen 2012, 66-68).

For our second dependent variable, a research assistant who was blind to the experimental randomization performed a search of LexisNexis Academic for media coverage in which the accuracy of specific claims made by a legislator were questioned. This Accuracy questioned measure is coded 1 if the research assistant found one or more articles or blog posts published during the study period in which 
specific factual claims made by the legislator were questioned by the author or other sources (including citations of past PolitiFact ratings) and 0 otherwise (intercoder reliability: 95\% agreement, Krippendorff's alpha=.876; see SM for further details on the search protocol, coding procedure, and types of articles found).

The third dependent variable is a binary measure that combines the first two dependent variables. It is coded as 1 if the accuracy of a statement by the legislator was questioned by PolitiFact or in an article in LexisNexis and 0 otherwise.

\section{Results}

Even with a dataset of nearly 1200 state legislators across nine states, fact-checks were relatively rare - only 27 state legislators in our data received ratings from PolitiFact state affiliates during the study period. Of these, 16 were "half true" or worse. Even with such small numbers, however, an inspection of the marginal distributions suggest that assignment to treatment had a significant effect, reducing the prevalence of negative ratings from 13 in the placebo and control conditions (1.7\%) to 3 in the treatment condition $(0.8 \%)$. Likewise, the number of legislators who had the accuracy of a claim questioned in media indexed in LexisNexis decreased from 8 in the placebo and control conditions $(1.0 \%)$ to 1 in the treatment group $(0.3 \%)$. There was no overlap in accuracy criticism between the measures. In all, 21 legislators in the placebo and control conditions had the accuracy of their claims questioned by PolitiFact or in Nexis (2.7\%) compared with 4 in the treatment condition $(1.0 \%)$.

To more formally evaluate our hypothesis, we estimated a series of weighted 
least squares regression models that account for the differing probability of treatment across blocks, which is necessary to obtain an unbiased estimate of the average effect of assignment to treatment for our experiment (Gerber and Green 2012, 117). ${ }^{7}$ We found no significant differences between the placebo and control conditions (see SM), suggesting that the differences in behavior we observe in the treatment condition are due to the fact-checking content in those mailings rather than a Hawthorne effect. To simplify exposition, we thus combine legislators in these conditions in the analyses below and estimate treatment effects relative to the control and placebo conditions. (All analyses are robust to estimating treatment effects relative to the placebo condition directly; see SM for details.)

In each model, we regressed our dependent variable on the treatment indicator using weighted least squares. Table 2 presents weighted means for the treatment and control groups as well as the results of these regression models, which estimate the average effect of assigned to the treatment condition (the average treatment effect [ATE]) on negative fact-checking ratings, other political figures, reporters, or commentators questioning the accuracy of legislators' claims, and a composite indicator for both outcome measures.

Our results indicate that legislators who were sent our treatment letters were substantially less likely to receive negative PolitiFact rating or to have their accuracy questioned publicly. While the treatment effect falls just short of significance at the $p<.05$ (one-tailed) for the negative PolitiFact rating, the effect is in the expected direction. For the Accuracy questioned variable, the treatment is significant

\footnotetext{
${ }^{7}$ Specifically, we follow Gerber and Green (2012) and weight treated observations by the inverse probability of treatment within each block while weighting placebo/control observations by $1 /(1-$ probability of treatment within each block). These weights were used in the weighted least squares regression estimates presented in the article text and supplementary materials.
} 
Table 2: Treatment effects of fact-checking threat letter

\begin{tabular}{lcccccc}
\hline & \multicolumn{2}{c}{ Weighted means } & & \multicolumn{3}{c}{ Risk reduction } \\
\cline { 2 - 6 } Outcome & Treatment & Control & ATE & $p$-val. & Absolute & Relative \\
\hline Negative PF rating & 0.008 & 0.017 & $\begin{array}{l}-0.009 \\
(0.006)\end{array}$ & .072 & $-0.9 \%$ & $-55 \%$ \\
Acc. questioned & 0.003 & 0.010 & $\begin{array}{c}-0.008 \\
(0.004)\end{array}$ & .042 & $-0.8 \%$ & $-75 \%$ \\
Combined measure & 0.010 & 0.027 & $\begin{array}{l}-0.017 \\
(0.007)\end{array}$ & .013 & $-1.7 \%$ & $-63 \%$ \\
\hline
\end{tabular}

Study sample consists of 1169 state legislators from nine states. Weighted means provided for treatment group and controls (the combined placebo/control group). Average treatment effect (ATE) estimated using weighted least squares regression with robust standard errors in parentheses; estimated $p$-values are one-sided due to the directional nature of our hypothesis. See text and supplementary materials for further details on treatments and outcome measures.

at the $p<.05$ level. Finally, when we combine the two outcome measures into a broader indicator of whether the accuracy of the legislator's claims are questioned, the treatment effect is highly significant $(p<.02)$. These results are consistent in a series of robustness checks presented in the SM (restricting the Negative PolitiFact rating measure to only take a value of 1 for "mostly false", "false", and "pants on fire" ratings; estimating treatment effects relative to the placebo condition; using logistic regression instead of weighted least squares; including block fixed effects; and using standard errors that are clustered by block).

In addition to the estimated treatment effects and standard errors, Table 2 also provides the absolute and relative magnitudes of the changes in predicted probability. Because we used a least squares estimator on a binary outcome measure, the treatment effect can be directly interpreted as a difference in means. The coefficients thus tells us how much the treatment reduced the probability of a negative outcome relative to the combined Hawthorne and control conditions. The estimated 
absolute risk reductions are relatively low $(0.8-1.7 \%)$ due to the infrequency with which state legislators were rated by PolitiFact or had their statements questioned in media or online outlets - a base rate that almost certainly understates the proportion of politicians who make misleading or inaccurate claims. By contrast, the estimated relative risk reductions in Table 2 are much larger (55-75\%), suggesting that the actual treatment effects are substantial. To highlight the extent of the relative risk reduction, Figure 2 contrasts the weighted means for our composite measure of reported inaccuracy between the treatment and placebo/control groups-a relative risk reduction of $63 \%$.

Figure 2: Probability of accuracy criticism (PolitiFact/LexisNexis)

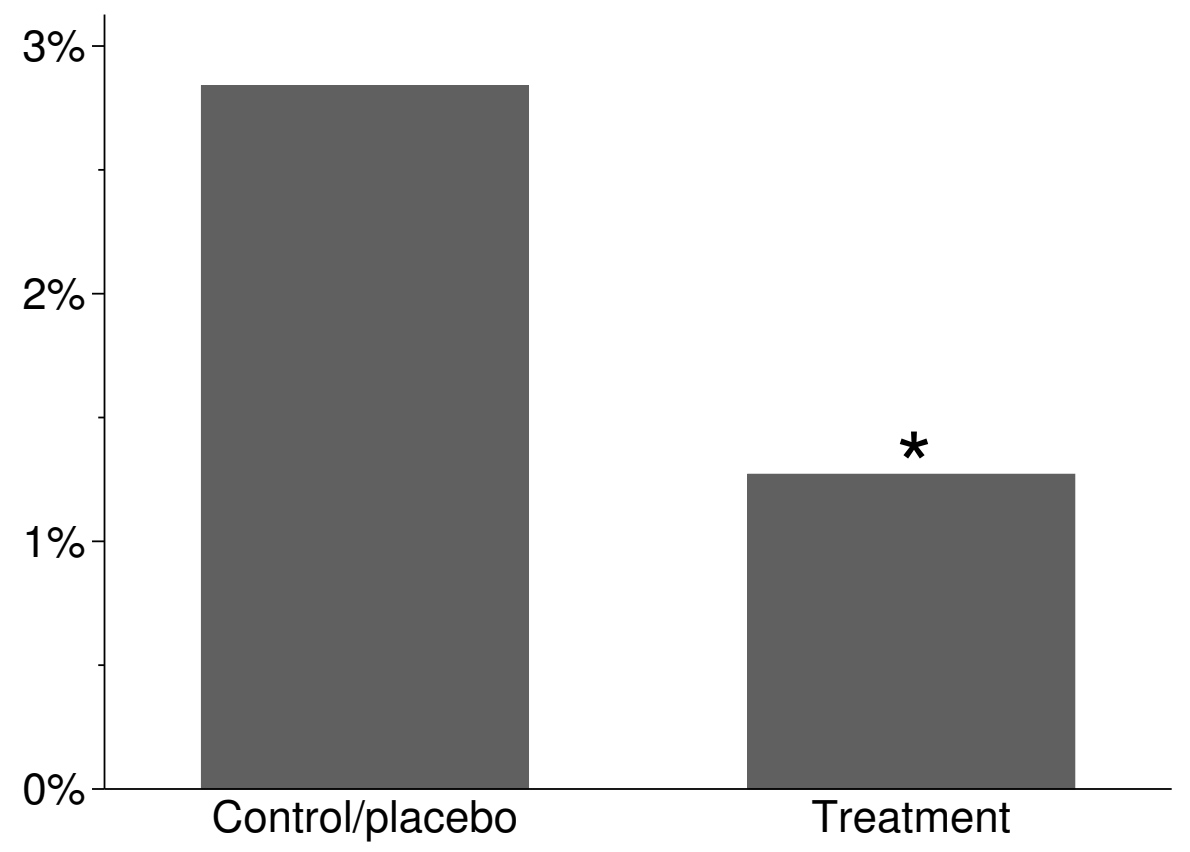

Legislators assigned to treatment condition are less likely to receive accuracy criticism. Study sample consists of 1169 state legislators from nine states. Weighted probabilities provided for treatment and placebo/control group. See text and supplementary materials for further details on treatments and outcome measures. 
To rule out the possibility that these effects were the result of the treatment suppressing public statements by legislators more generally, we estimated weighted least squares regression models of the probability of receiving any rating from PolitiFact, the total number of articles found for each legislator in Nexis excluding the accuracy-related keywords used in Accuracy questioned, and the number of pages on each legislator's website when scraped approximately one week after the election (a proxy for the total volume of content provided). As Table 3 indicates, none of these results were statistically significant, suggesting that the treatment did not suppress speech, but changed it.

Table 3: Treatment effects for indicators of volume of speech

\begin{tabular}{lccc}
\hline Model & Received PF rating & Total Nexis articles & Number webpages \\
\hline Treatment & -0.003 & 1.803 & 0.075 \\
& $(0.008)$ & $(1.221)$ & $(3.131)$ \\
Constant & 0.021 & 9.317 & 21.354 \\
& $(0.005)$ & $(0.605)$ & $(2.099)$ \\
$\mathrm{R}^{2}$ & 0.00 & 0.00 & 0.00 \\
$\mathrm{~N}$ & 1169 & 1169 & 789 \\
\hline
\end{tabular}

Weighted least squares regression with robust standard errors in parentheses. Number of webpages calculated as the number of files ending in .html, .shtml, .php, .htm, .asp, or .php that were successfully scraped by an automated program on November 13, 2012 from the candidate's website when one could be located. Facebook or Twitter accounts were excluded.

Finally, it is important to reiterate that our experiment estimates the effect of assigning a legislator to the treatment condition. The magnitude of the effect of actually reading the letter increases as the proportion of legislators in the treatment condition who were not successfully reached increases. We cannot observe this quantity, but Figure 3 illustrates how the estimated effect of receiving the treatment increases as the assumed level of non-compliance increases. As reference points, it provides three possible measures of this unknown quantity based on the rate at 
which recipients of treatment and placebo letters signed and returned an enclosed postage-paid acknowledgment postcard or the proportion of letters that were not returned as undeliverable.

Figure 3: Effect of reading treatment letter on treated legislators (PF/Nexis)

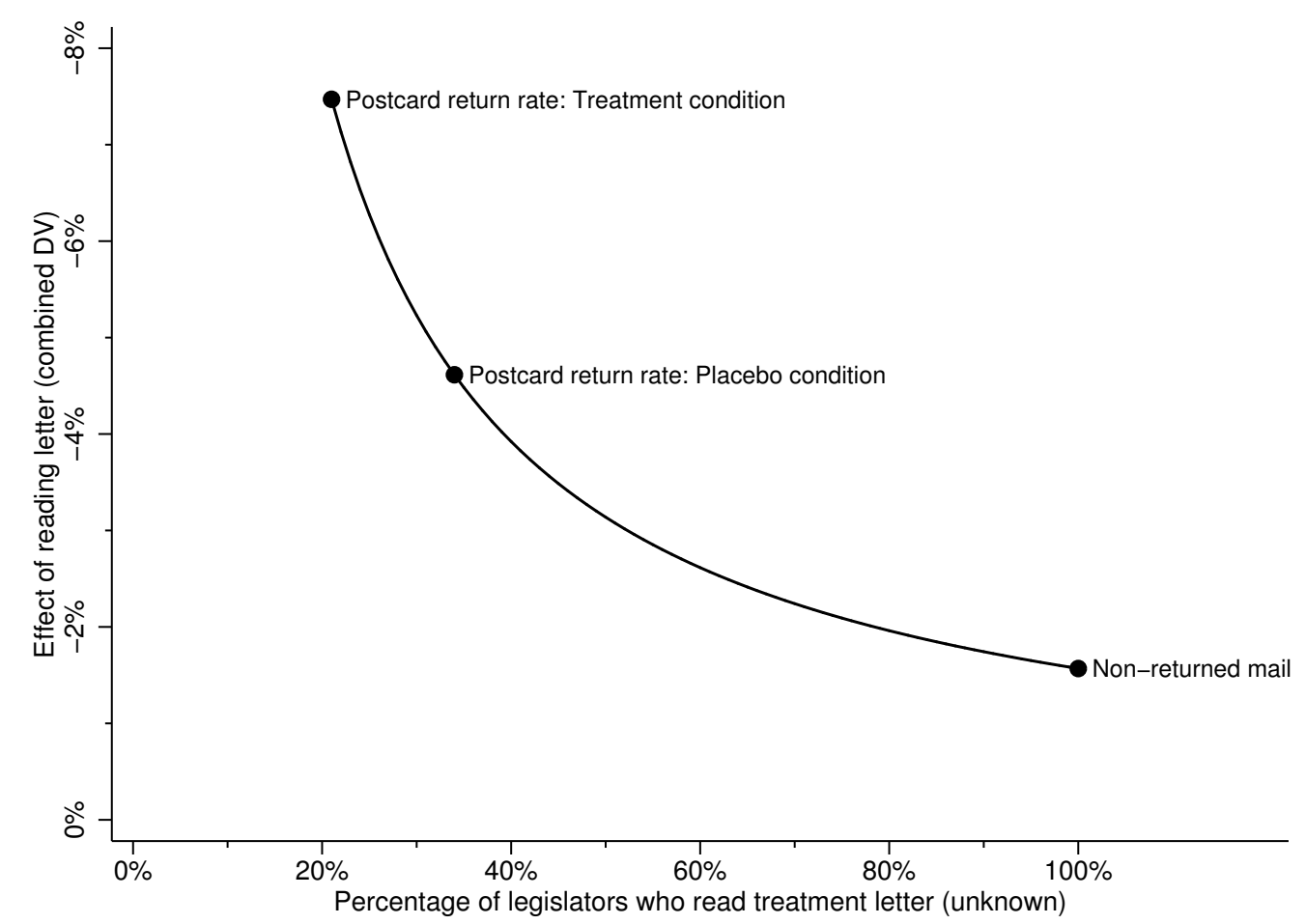

Possible range of absolute effect estimates for the average effect of treatment on the treated. Calculated by dividing the effect size from combined PolitiFact/LexisNexis measure in Table 2 by the hypothetical proportion of legislators in treatment condition who actually read the letter. See text and supplementary materials for further details on treatments and outcome measures.

The magnitude of the average treatment effect on the treated is easily calculated under various assumptions about the ratio of legislators who were successfully treated (the treatment effect for all others is assumed to be zero). For instance, if $50 \%$ of legislators in the treatment group did not read the letter, the treatment effect 
on the combined measure for those who did read the letter is twice as large as the effect of assignment to treatment $(-1.7 \% / .5=-3.4 \%)$. Similarly, the effect is four times as large if $75 \%$ did not read the letter $(-1.7 \% / .25=-6.8 \%)$.

\section{Discussion}

Does external monitoring reduce inaccuracy in statements made by political elites? In the first field experiment of its kind, we find that the randomized provision of a series of letters highlighting the electoral and reputational risks of having questionable statements exposed by fact-checkers significantly reduced the likelihood that legislators in nine U.S. states would receive a negative fact-checking rating or have the accuracy of their claims questioned publicly. We found no evidence that these results were driven by legislators speaking less frequently or receiving less coverage, suggesting instead that they were less likely to make inaccurate statements rather than being silenced more generally.

Moreover, these results, while encouraging, may understate the magnitude of the potential effects of fact-checking on the behavior of politicians or other elites. First, we can only estimate the effect of being assigned to receive the treatment letter. It is unlikely that every state legislator to whom we sent the treatment letter received it and read it carefully. If the negative consequences of inaccurate statements were salient and accessible to all elites, the potential effects on their behavior would likely be even larger. In addition, the magnitude of the treatment effects are scaled relative to the low base rate of fact-checking or articles questioning a legislator's accuracy, which is likely to capture only a tiny fraction of the deceptive 
or inaccurate statements that politicians make. If the frequency of inaccurate statements is much higher in practice, our relative risk reduction estimates suggest that the potential effect of fact-checking threat is sizable.

Future research should investigate the mechanisms by which fact-checking change elite behavior and the extent to which they are captured in our experimental design. For instance, fact-checkers may change elite behavior by increasing the perceived risks of making misleading claims and/or priming normative concerns about truthfulness. Our experimental design does not allow us to evaluate potential mediators, though our treatment letter could plausibly have both effects. Another possibility is that the effects of fact-checking may vary due to state-level or contextual factors such as whether the legislature is in session. With only nine states in our sample (all of which were out of session during our study), we cannot answer these questions, but they are worth considering as fact-checking continues to expand.

More generally, these results indicate that fact-checking should not be discredited by the continued prevalence of misinformation and misperceptions. While factchecking may be ineffective at changing public opinion, its role as a monitor of elite behavior may justify the continued investment of philanthropic and journalistic resources. Indeed, given the very small numbers of legislators whose accuracy is currently being questioned by fact-checkers or other sources, one could argue that fact-checking should be expanded in the U.S. so that it can provide more extensive and consistent monitoring to politicians at all levels of government. 


\section{References}

Adair, Bill. 2013. "PolitiFact expands to Australia." Tampa Bay Times.

Alcorn, Gay. 2013. “Welcome.” The Conversation. July 8, 2013. Downloaded July 22, 2013 from http: / / theconversation.com/welcome-15870.

Amazeen, Michelle. 2012. "Blind spots: Examining political advertising misinformation and how U.S. news media hold political actors accountable." Ph.D. dissertation, Temple University.

Arnold, R. Douglas. 2004. Congress, the press, and political accountability. Princeton University Press.

Balz, Dan. 2012. "President Obama, Mitt Romney running a most poisonous campaign.” Washington Post, August 15, 2012.

Bergan, Daniel E. 2009. "Does grassroots lobbying work? A field experiment measuring the effects of an e-mail lobbying campaign on legislative behavior." American Politics Research 37 (2): 327-352.

Broockman, David E. 2013. "Black Politicians Are More Intrinsically Motivated to Advance Blacks' Interests: A Field Experiment Manipulating Political Incentives." Forthcoming, American Journal of Political Science.

Butler, Daniel M. 2010. "Monitoring Bureaucratic Compliance: Using Field Experiments to Improve Governance.” Public Sector Digest Winter (41-44).

Butler, Daniel M., Christopher F. Karpowitz, and Jeremy C. Pope. 2012. “A Field 
Experiment on Legislators' Home Styles: Service versus Policy." Journal of Politics 1 (1): 1-13.

Butler, Daniel M., and David E. Broockman. 2011. "Do politicians racially discriminate against constituents? A field experiment on state legislators." American Journal of Political Science 55 (3): 463-477.

Butler, Daniel M., and David W. Nickerson. 2011. "Can Learning Constituency Opinion Affect How Legislators Vote? Results from a Field Experiment.” Quarterly Journal of Political Science 6 (1): 55-83.

Campante, Filipe Robin, and Quoc-Anh Do. 2013. "Isolated Capital Cities, Accountability and Corruption: Evidence from US States." National Bureau of Economic Research working paper.

Carr, David. 2012. “A Last Fact Check: It Didn’t Work.” New York Times.

Cunningham, Brent. 2003. "Re-thinking objectivity." Columbia Journalism Review 42 (2): $24-32$.

Duflo, Esther, Rachel Glennerster, and Michael Kremer. 2007. "Using randomization in development economics research: A toolkit." Handbook of Development Economics 4: 3895-3962.

Duflo, Esther, Rema Hanna, and Stephen P. Rya. 2012. "Incentives work: Getting teachers to come to school." American Economic Review 102 (4): 1241-1278.

Fenno, Richard F. 2002. Home Style: House Members in Their Districts (Longman Classics Series). Longman Publishing Group. 
Ferraz, Claudio, and Frederico Finan. 2008. "Exposing Corrupt Politicians: The effects of Brazil's publicly released audits on electoral outcomes." Quarterly Journal of Economics 123 (2): 703-745.

Fritz, Ben, Bryan Keefer, and Brendan Nyhan. 2004. All the President's Spin: George W. Bush, the media, and the truth. Touchstone Books.

Gentzkow, Matthew, Jesse M. Shapiro, and Michael Sinkinson. 2011. "The Effect of Newspaper Entry and Exit on Electoral Politics." American Economic Review 101 (7): 2980-3018.

Gerber, Alan S., and Donald P. Green. 2012. Field experiments: Design, analysis, and interpretation. W. W. Norton \& Company.

Gottfried, Jeffrey A., Bruce W. Hardy, Kenneth M. Winneg, and Kathleen Hall Jamieson. 2013. "Did Fact Checking Matter in the 2012 Presidential Campaign?" American Behavioral Scientist.

Graves, Lucas. 2013. "Deciding What's True: Fact-Checking Journalism and the New Ecology of News." Ph.D. dissertation, Columbia University.

Graves, Lucas, and Tom Glaisyer. 2012. "The Fact-Checking Universe in Spring 2012: An Overview.” New America Foundation Media Policy Initiative Research Paper.

Grose, Christian. N.d. "A Field Experiment of Participatory Shirking Among Legislators: Pressuring Representatives to Show up for Work." Unpublished manuscript. 
Humphreys, Macartan, and Jeremy Weinstein. N.d. "Policing politicians: Citizen empowerment and political accountability in Uganda." Unpublished manuscript.

Iyengar, Shanto, and Kyu S. Hahn. 2009. "Red media, blue media: Evidence of ideological selectivity in media use." Journal of Communication 59 (1): 19-39.

Iyengar, Shanto, Kyu S. Hahn, Jon A. Krosnick, and John Walker. 2008. "Selective exposure to campaign communication: The role of anticipated agreement and issue public membership." Journal of Politics 70 (01): 186-200.

Levitt, Steven D., and John A. List. 2011. "Was there really a Hawthorne effect at the Hawthorne plant? An analysis of the original illumination experiments." American Economic Journal: Applied Economics 3 (1): 224-238.

Lewandowsky, Stephan, Ullrich K.H. Ecker, Colleen M. Seifert, Norbert Schwarz, and John Cook. 2012. "Misinformation and its correction: Continued influence and successful debiasing." Psychological Science in the Public Interest 13 (3): $106-131$.

Loewen, Peter John, and Daniel Rubenson. 2011. "For want of a nail: Negative persuasion in a party leadership race.” Party Politics 17 (1): 45-65.

Loewen, Peter, and Michael K. MacKenzie. N.d. "Representation in a Federal System: A Field Experiment.” Unpublished manuscript.

Malesky, Edmund, Paul Schuler, and Anh Tran. 2012. "The Adverse Effects of Sunshine: A Field Experiment on Legislative Transparency in an Authoritarian Assembly.” American Political Science Review 106 (4): 762-786. 
Marx, Greg. 2012. "What the Fact-Checkers Get Wrong: The language of Politifact and its peers doesn't match their project." Columbia Journalism Review Campaign Desk.

Mayhew, David R. 1974. Congress: The electoral connection. Yale University Press.

McClendon, Gwyneth H. N.d. "Social Esteem And Participation In Contentious Politics.” Unpublished manuscript.

Moore, Ryan T. 2012. "Multivariate continuous blocking to improve political science experiments.” Political Analysis 20 (4): 460-479.

Moore, Ryan T. N.d. "blockTools: Blocking, Assignment, and Diagnosing Interference in Randomized Experiments.” Version 0.5-6, August 2012.

Myers, Steve. N.d. "PolitiFact Takes Lesson from Fast-Food Industry as it Franchises Fact Checking." Poynter Institute, May 3, 2010. Downloaded June 25, 2013 from http://www . poynter.org/latest-news/top-stories/102422/ politifact-takes-lesson-from-fast-food-industry-as-it-franchises-fac

Nyhan, Brendan. 2010. "Why the 'death panel' myth won't die: Misinformation in the health care reform debate." The Forum 8 (1).

Nyhan, Brendan. 2012. "Another factchecking fiasco: Journalistic failure in coverage of Harry Reid and his mysterious source." Columbia Journalism Review United States Project. 
Nyhan, Brendan. 2013a. "Bill Adair, setting pants ablaze no more: The PolitiFact founder on his move to academia and the state of the factchecking movement." Columbia Journalism Review U.S. Project.

Nyhan, Brendan. 2013b. “That's not a factcheck! How punditry undermines the mission of journalistic watchdogs." Columbia Journalism Review United States Project.

Nyhan, Brendan, and Jason Aaron Reifler. 2012. "Misinformation and Factchecking: Research Findings from Social Science.” New America Foundation Media Policy Initiative Research Paper.

Nyhan, Brendan, and Jason Reifler. 2010. "When Corrections Fail: The persistence of political misperceptions." Political Behavior 32 (2): 303-330.

Nyhan, Brendan, Jason Reifler, and Peter A. Ubel. 2013. "The hazards of correcting myths about health care reform." Medical Care 51 (2): 127-132.

Olken, Benjamin A. 2007. "Monitoring Corruption: Evidence from a Field Experiment in Indonesia." Journal of Public Economics 115 (21): 200-249.

PolitiFact.com. N.d. “About PolitiFact.” Downloaded June 12, 2013 from http: //www.politifact.com/about/.

Prior, Markus. 2006. "The incumbent in the living room: The rise of television and the incumbency advantage in US House elections." Journal of Politics 68 (3): $657-673$. 
Schulhofer-Wohl, Sam, and Miguel Garrido. 2009. "Do newspapers matter? Evidence from the closure of The Cincinnati Post." National Bureau of Economic Research working paper.

Smith, Ben. 2012. "Romney Camp Bets On Welfare Attack." Buzzfeed.

Snyder, James M., and David Strömberg. 2010. "Press Coverage and Political Accountability." Journal of Political Economy 118 (2): 355-408.

Stroud, Natalie Jomini. 2008. "Media use and political predispositions: Revisiting the concept of selective exposure." Political Behavior 30 (3): 341-366.

Taber, Charles S., and Milton Lodge. 2006. "Motivated Skepticism in the Evaluation of Political Beliefs.” American Journal of Political Science 50 (3): 755-769.

Tetlock, Philip. 2005. Expert political judgment: How good is it? How can we know? Princeton University Press. 